\title{
Enhancement of the thermal conductivity of sands via microbially-induced calcite precipitation
}

\author{
Alejandro Martinez ${ }^{1, *}$, Lin Huang ${ }^{1}$, and Michael G. Gomez ${ }^{2}$ \\ ${ }^{1}$ University of California Davis, Civil and Environmental Engineering, 2001 Ghausi Hall, Davis, CA, USA, 95616 \\ ${ }^{2}$ University of Washington, Civil and Environmental Engineering, 132G More Hall, Seattle, WA, USA, 98195
}

\begin{abstract}
Energy piles and ground source heat pump systems have been shown to provide sustainable alternatives for temperature regulation in buildings and other applications such as road de-icing. However, their efficiency can be undermined in partially-saturated and dry sandy soils due to the relatively low thermal conductivity $\left(\mathrm{k}_{\mathrm{t}}\right)$ of these materials. Microbially-Induced Calcite Precipitation (MICP) has been demonstrated to be an environmentally-conscious ground improvement technology capable of modifying the engineering properties of sandy soils including increases in shear stiffness and strength and decreases in hydraulic conductivity. These improvements result from the precipitation of calcium carbonate crystals at inter-particle contacts and on particle surfaces. This paper presents results from a soil column study aimed at investigating changes in soil $\mathrm{k}_{\mathrm{t}}$ during MICP treatments and subsequent desaturation using a poorlygraded sand. The results indicate that while bio-cementation can increase soil $\mathrm{kt}$, the level of enhancement depends on the degree of saturation. For instance, increases of up to $330 \%$ were measured under dry conditions while only modest increases of about $15 \%$ were measured under saturated conditions. MICP treatment may therefore be most effective at enhancing the $\mathrm{k}_{\mathrm{t}}$ of partially-saturated and dry sands. In addition, the similarity between the evolution of $\mathrm{k}_{\mathrm{t}}$ and shear wave velocity $\left(\mathrm{V}_{\mathrm{s}}\right)$ during MICP treatment suggests that $\mathrm{k}_{\mathrm{t}}$ may provide a new method to assess cementation level and contact quality.
\end{abstract}

\section{Introduction}

Energy piles and ground source heat pump systems have been shown to provide sustainable energy for temperature regulation in buildings and for other applications such as bridge de-icing (e.g. [1, 2]). The efficiency of these systems in terms of heat transfer depends on the configuration of the circulation tubes, the thermal properties of the circulating fluid, and the thermal properties of the surrounding soils (e.g. [1]). Heat transfer through soils takes place primarily through the solid and liquid phases. The thermal conductivity $\left(\mathrm{k}_{\mathrm{t}}\right)$ is the soil property that controls heat transfer, and its magnitude is dependent on the $\mathrm{k}_{\mathrm{t}}$ of the different phases present in a given soil. The magnitude of $\mathrm{k}_{\mathrm{t}}$ of the different phases in sandy soils are as follows: $\mathrm{k}_{\text {quartz }}(\sim 7$ $\mathrm{W} / \mathrm{mK})>\mathrm{k}_{\text {saturated,sand }}(\sim 3 \mathrm{~W} / \mathrm{mK})>\mathrm{k}_{\text {water }}(\sim 0.6 \mathrm{~W} / \mathrm{mK})>$ $\mathrm{k}_{\text {dry,sand }}(\sim 0.3 \mathrm{~W} / \mathrm{mK})>\mathrm{k}_{\text {air }}(0.02 \mathrm{~W} / \mathrm{mK})$. Consequently, the presence of water can increase the $\mathrm{k}_{\mathrm{t}}$ of sands by an order of magnitude.

Soil thermal conductivity depends on the mineralogy, type of pore fluid, and other aspects that determine the interconnectivity between particle contacts and fluidfilled pores, such as density, gradation, particle size and shape, and degree of saturation (e.g. [3-9]). Models have been developed to predict the effect of degree of saturation on the soil thermal conductivity (e.g. [10-16]). However, less attention has been devoted to the effect of cementation. Recently, Venuleo et al. and Martinez et al. $[17,18]$ showed that Microbially-Induced Calcite Precipitation (MICP), a process through which calcium carbonate is precipitated on particle contacts and surfaces by bacteria, can increase the thermal conductivity of sands by up to $300 \%$. However, the magnitude of this increase was shown to depend on the degree of saturation. The goal of the investigation presented herein is to evaluate the ability of MICP treatment to increase the $\mathrm{k}_{\mathrm{t}}$ of a quartz sand and to shed light on other related mechanisms such as the relationship between shear wave velocity, $\mathrm{V}_{\mathrm{S}}$, and $\mathrm{k}_{\mathrm{t}}$ and the effect of biocementation on the water retention properties of sandy soils.

\section{Materials and methods}

Sand specimens were treated with MICP and the evolution of their $\mathrm{k}_{\mathrm{t}}$ during treatment and subsequent desaturation was monitored. A detailed description of the experimental methods can be found in [18]. However, a brief description is provided here.

The experiments took place in polytetrafluoroethylene (PFTE) soil columns with an inner diameter and height of about $70 \mathrm{~mm}$ and $140 \mathrm{~mm}$, respectively, as shown in Fig. 1. The columns had ports for pore fluid sampling and installation of sensors. In addition, the bottom of the sand specimens were in

\footnotetext{
* Corresponding author: $\underline{\text { amart } @ \text { ucdavis.edu }}$
} 
contact with an HDPE filter and a ceramic disk with an air entry value (AEV) of $50 \mathrm{kPa}$. A total of five columns were tested; four columns were treated to achieve varying degrees of biocementation and a fifth control column remained uncemented.

The sand used in all experiments was Ottawa 50-70 (U.S. Silica), a quartz poorly-graded sand. The sand has a mean particle diameter of $0.26 \mathrm{~mm}$, a coefficient of uniformity of 1.24 , a specific gravity of 2.65 , and minimum and maximum porosities of 0.37 and 0.46 . The sand columns were compacted in 8 lifts of equal height by light tamping to a target initial porosity of 0.38 . A vertical load of $50 \mathrm{kPa}$ was applied on each column. The sand was compacted around the needle sensor used to measure the $\mathrm{k}_{\mathrm{t}}$ of the specimens. The $\mathrm{k}_{\mathrm{t}}$ was measured with a TR-1 needle sensor with a diameter and height of $2.4 \mathrm{~mm}$ and $100 \mathrm{~mm}$, respectively, and a KD2 Pro Thermal Properties Analyzer (Decagon Devices). Horizontal bender elements were also included in two columns to monitor the changes in shear wave velocity during MICP treatment. The shear wave velocity was determined based on the travel time between the peak input and output shear wave signals.
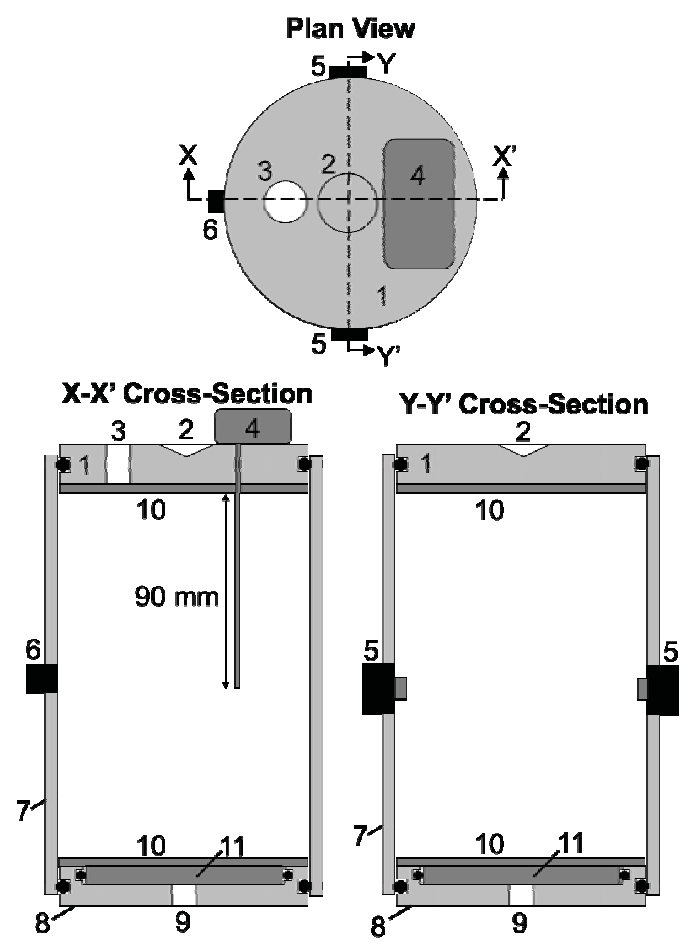

Fig. 1. Column used for MICP treatment $(1-$ top cap, 2 bearing notch for vertical load, 3 - outflow port, 4 - thermal needle sensor, 5 - bender elements, 6 - pore fluid sampling septa port, 7 - PFTE column, 8 - bottom cap, 9 - inflow port, 10 - HDPE filters, 11 - ceramic disc).

Four saturated soil columns were subjected to MICP treatments. Columns were first augmented (i.e. treated) with the ureolytic bacterium, Sporosarcina pasteurii ( $S$. pasteurii), to enable the biocementation process. $S$. pasteurii cells were cultured in a sterile alkaline medium containing $20 \mathrm{~g} / \mathrm{L}$ yeast extract, $75 \mathrm{mM}$ ammonium sulfate, and $130 \mathrm{mM}$ tris base. Following incubation, cultured growth media was diluted in sterile saline $(9 \mathrm{~g} / \mathrm{L}$ $\mathrm{NaCl})$ to achieve a final $S$. pasteurii cell density of $2.5 \mathrm{x}$ $10^{8}$ cells $/ \mathrm{mL}$. $250 \mathrm{~mL}$ of this augmentation solution was applied to each column and was recirculated 5 times. Augmentation solutions resided within all columns for 24 hours. After augmentation, $250 \mathrm{~mL}$ of a solution containing $0.2 \mathrm{~g} / \mathrm{L}$ yeast extract, $100 \mathrm{mM} \mathrm{NH}_{4} \mathrm{Cl}$ and $350 \mathrm{mM}$ urea was applied to all columns to remove metabolic waste, saline solution, and growth media. Immediately following this injection, $300 \mathrm{~mL}$ of a cementation solution containing $0.2 \mathrm{~g} / \mathrm{L}$ yeast extract, $100 \mathrm{mM} \mathrm{NH} \mathrm{Cl}_{4}, 350 \mathrm{mM}$ urea, and $250 \mathrm{mM}$ calcium chloride was applied to each column. Cementation injections were applied once daily for periods between 2 to 15 days depending on the targeted level of cementation. Urea degradation and calcite precipitation was monitored using $\mathrm{pH}$ measurements during all treatments. The $\mathrm{pH}$ measurements were made on pore fluid samples using a laboratory grade $\mathrm{pH}$ probe. All columns remained saturated during these treatments.

Following biocementation treatments, columns were subsequently desaturated using two methods. Initially, the columns were subjected to suction levels between 0 and $5 \mathrm{kPa}$ using a hanging column setup, as described in $[6,18,19]$. The suction was created by a difference in elevation head between the test column and a reference source of atmospheric pressure, and the water outflow was measured with a burette. This configuration was used to determine the AEV and to obtain one scanning curve for each of the five columns. After re-saturation of the columns by continuous water flow, they were placed in an oven at a controlled temperature $\left(60\right.$ to $\left.100^{\circ} \mathrm{C}\right)$ and humidity (10 to $20 \% \mathrm{RH})$. The column masses and $\mathrm{k}_{\mathrm{t}}$ were measured at set times after the columns were taken out of the oven and allowed to reach thermal equilibrium for at least eight hours. It is noted that the degree of saturation values reported throughout this paper correspond to averages along the soil columns. For this reason, the hanging column tests were mainly used to determine the AEV. However, the moisture distribution inside the columns is believed to be relatively uniform during oven drying, as evidenced by internal moisture content sensors placed in a separate control column.

\section{Results}

\subsection{MICP treatment}

Four saturated columns were subjected to MICP treatment and a control column was left untreated. The treated columns were subjected to $2,9,11$, and 15 daily cementation treatments; these columns are numbered from 1 to 4 in increasing number of treatments (e.g. Column 1 received 2 treatments and Column 4 received 15 treatments). Monitoring of all the columns included daily measurements of thermal conductivity and pore fluid $\mathrm{pH}$. In addition, Columns 3 and 4 also included bender elements for shear wave velocity measurements.

Fig. 2a presents the evolution of $\mathrm{k}_{\mathrm{t}}$ during treatment for the four columns. As shown, $\mathrm{k}_{\mathrm{t}}$ increases with treatment days for all columns. However, the $\mathrm{k}_{\mathrm{t}}$ values 
appear to reach a constant value the day after the final treatment (e.g. day 3 for Column 1, day 10 for Column 2). The pre-treatment $\mathrm{k}_{\mathrm{t}}$ value was between 3.06 to 3.10 $\mathrm{W} / \mathrm{mK}$ for all the columns and reached a value of 3.48 $\mathrm{W} / \mathrm{mK}$ at the end of treatment for Column 4 . Increasing cementation results in growth of the solid phase within the column (i.e. decrease in porosity). Since calcite has a greater $\mathrm{k}_{\mathrm{t}}$ than water $\left(\mathrm{k}_{\mathrm{t}, \text { calcite }} \sim 5 \mathrm{~W} / \mathrm{mK}\right)$, this results in an increase in the bulk $\mathrm{k}_{\mathrm{t}}$. When examining $\mathrm{pH}$ trends shown in Fig. 2b, pH values increased to near 9.3 in all columns after day one resulting from the application of the high $\mathrm{pH}$ augmentation solutions. For all subsequent days during cementation, post-treatment $\mathrm{pH}$ values approached lower values near 8.7. This reduction in $\mathrm{pH}$ resulted from solution buffering by calcium carbonate precipitation despite near full urea hydrolysis.
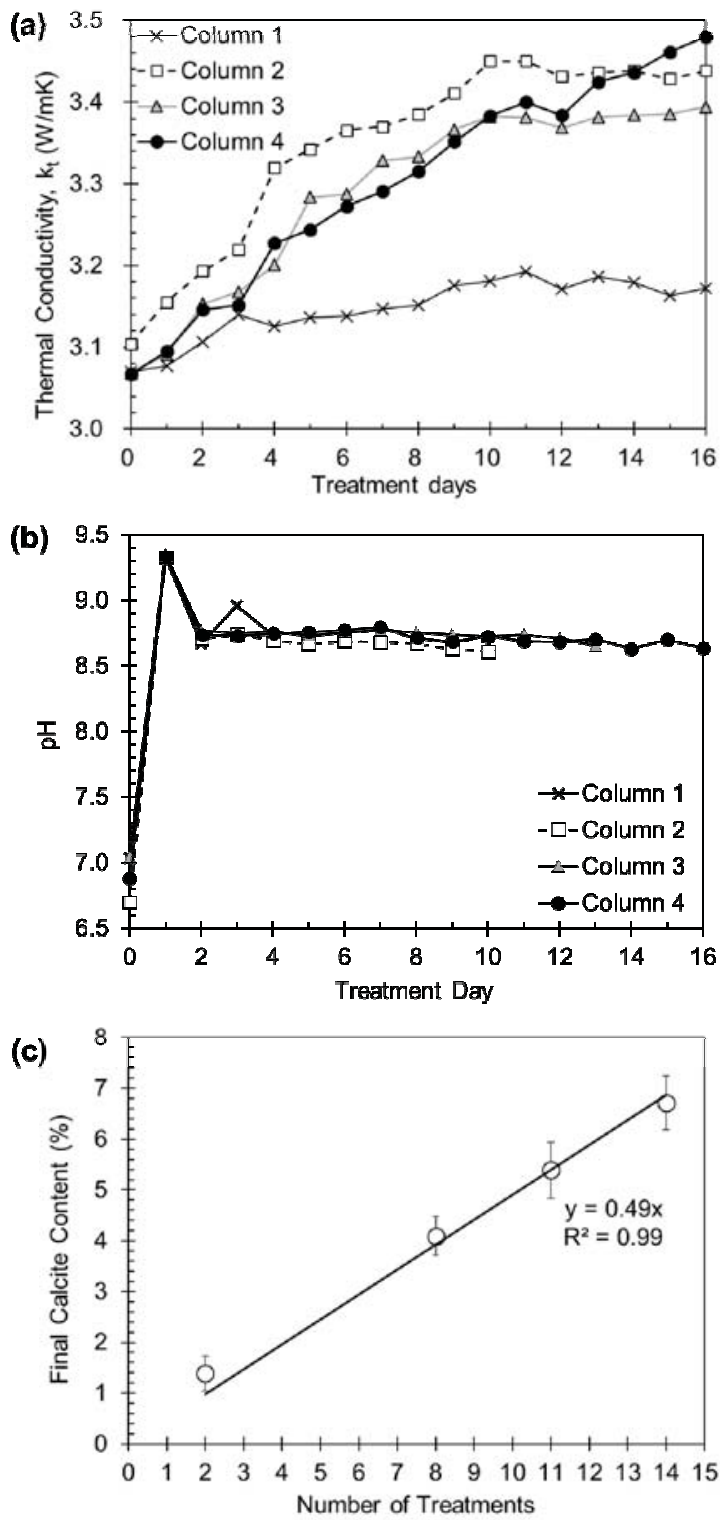

Fig. 2. MICP treatment of four sand columns: (a) thermal conductivity, (b) $\mathrm{pH}$, and (c) final calcite content (error bars show standard deviation of measurements from different locations within samples). Note: the sudden increase in $\mathrm{pH}$ for column 1 in day 3 is believed to reflect an incorrect reading.
At the end of the experimental program, each column was dissected to obtain 11 samples from uniformlydistributed locations for Calcite Content (CC) measurements. These measurements were obtained following the ASTM D4373-14 standard by reacting soil samples with $1 \mathrm{M} \mathrm{HCl}$ acid. As shown in Fig. 2c, the relationship between $\mathrm{CC}$ and number of $\mathrm{MICP}$ treatments is linear and $\mathrm{CC}$ increased at an average rate of $0.49 \%$ per treatment day.

The shear wave velocity of Columns 3 and 4 was also measured daily. The relationship between the $V_{S}$ and $\mathrm{k}_{\mathrm{t}}$ measurements is linear, as presented in Fig. 3. This trend is likely because both parameters depend on the area of interparticle contacts (e.g. [4, 20]), which increases during MICP treatment. These results suggest that $\mathrm{k}_{\mathrm{t}}$ can be used in a similar way as $\mathrm{V}_{\mathrm{S}}$ during MICP treatment to monitor cementation level and particle contact quality. However, it is noted that the presence of water significantly affects $\mathrm{k}_{\mathrm{t}}$ measurements, as described in the following sections

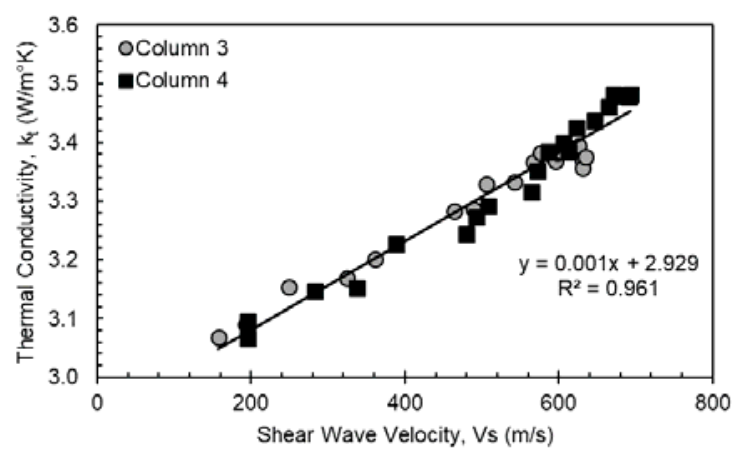

Fig. 3. Evolution of thermal conductivity and shear wave velocity during MICP treatment.

\subsection{Evolution of thermal conductivity during environmental chamber desaturation}

The thermal conductivity was larger for the more heavily cemented columns across all saturation levels, as shown in Fig. 4. As the columns were desaturated from $100 \%$ to about $10 \%$, the decrease in $\mathrm{k}_{\mathrm{t}}$ was relatively steady. However, at lower saturation values the $\mathrm{k}_{\mathrm{t}}$ decreased dramatically. This behavior is characteristic of poorlygraded sands where at larger saturation levels the transfer of heat is controlled by convection through the water phase and through interparticle contacts [16]. In this regime, the air that is introduced in the system reduces the area of water through which heat can be transferred. The sudden decrease in $\mathrm{k}_{\mathrm{t}}$ at lower saturation levels marks the transition from the funicular to the pendular regime, at which the water phase becomes discontinuous and heat is primarily transferred through grain-grain contacts and through grain-water paths (e.g. $[10,12,13,15,16])$. 


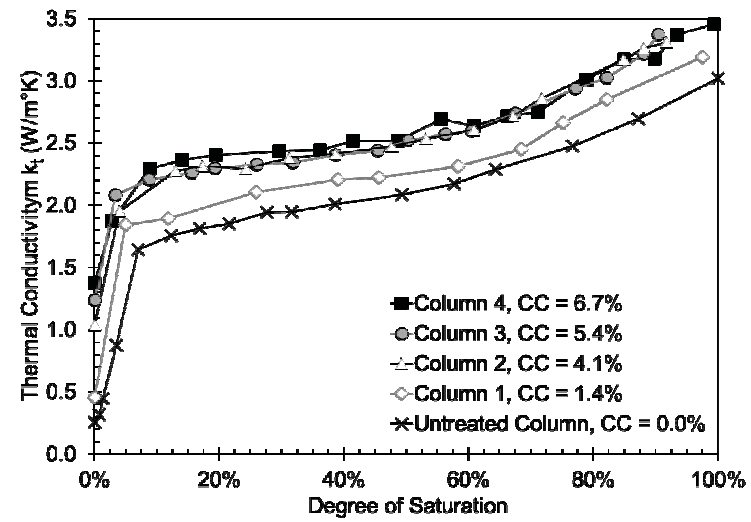

Fig. 4. Evolution of thermal conductivity during desaturation.

The results indicate that for a given degree of saturation, the relationship between $\mathrm{k}_{\mathrm{t}}$ and $\mathrm{CC}$ can be described with a linear function as shown in Fig. 5. The slope of this relationship is greatly affected by the degree of saturation, where the slope has values between 0.06 and $0.08 \mathrm{~W} / \mathrm{mK} / \% \mathrm{CC}$ for degree of saturation values larger than $30 \%$. However, the slope rapidly increases at lower degrees of saturation, taking a maximum value of 0.17 $\mathrm{W} / \mathrm{mK} / \%$ for dry sand. The dependency of $\mathrm{k}_{\mathrm{t}}$ on CC and degree of saturation can be observed in Fig. 6 which presents a surface plot of interpolated $\mathrm{k}_{\mathrm{t}}$ values.

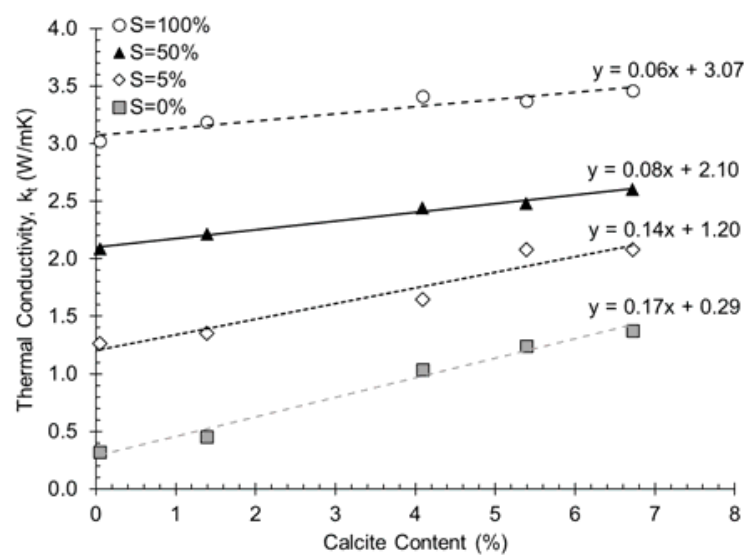

Fig. 5. Relationship between thermal conductivity and calcite content at constant degrees of saturation.

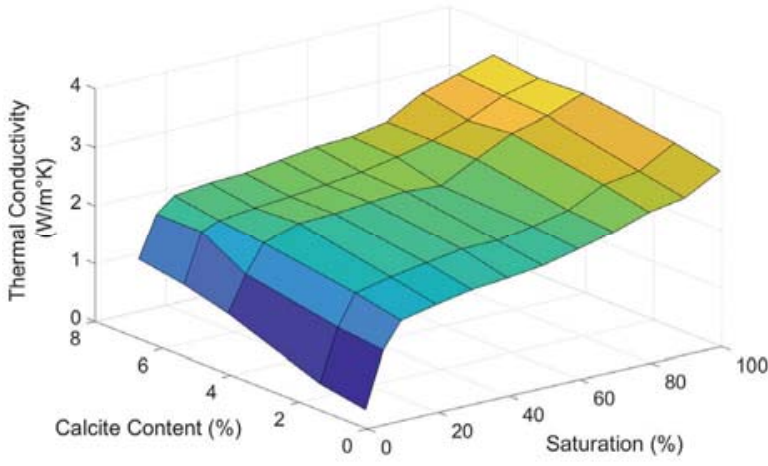

Fig. 6. Relationship between thermal conductivity, calcite content and degree of saturation. Note: the colors represent the thermal conductivity values, with darker blue representing lower values.
The degree of saturation of the columns influenced the sensitivity of $\mathrm{k}_{\mathrm{t}}$ to increases in CC. Consequently, the increase in thermal conductivity relative to the control untreated column, calculated as $\Delta \mathrm{k}_{\mathrm{t}}=\left(\mathrm{k}_{\mathrm{t}, \text { cemented }}\right.$ $\left.\mathrm{k}_{\mathrm{t}, \text { untreated }}\right) / \mathrm{k}_{\mathrm{t}, \text { untreated, was significantly greater at lower }}$ degrees of saturation. For instance, cementation to a CC of $6.7 \%$ resulted in an increase in $\mathrm{k}_{\mathrm{t}}$ of roughly $15 \%$ in saturated conditions. On the other hand, the corresponding increase in $\mathrm{k}_{\mathrm{t}}$ in dry conditions was about $330 \%$. Fig. 7 presents $\Delta \mathrm{k}_{\mathrm{t}}$ values as a function of CC for various degrees of saturation. As shown, the $\Delta \mathrm{k}_{\mathrm{t}}$ values increase slowly as the degree of saturation is decreased from $100 \%$ to $10 \%$. However, a large increase in $\Delta \mathrm{k}_{\mathrm{t}}$ is observed at degrees of saturation of $5 \%$ and $0 \%$.

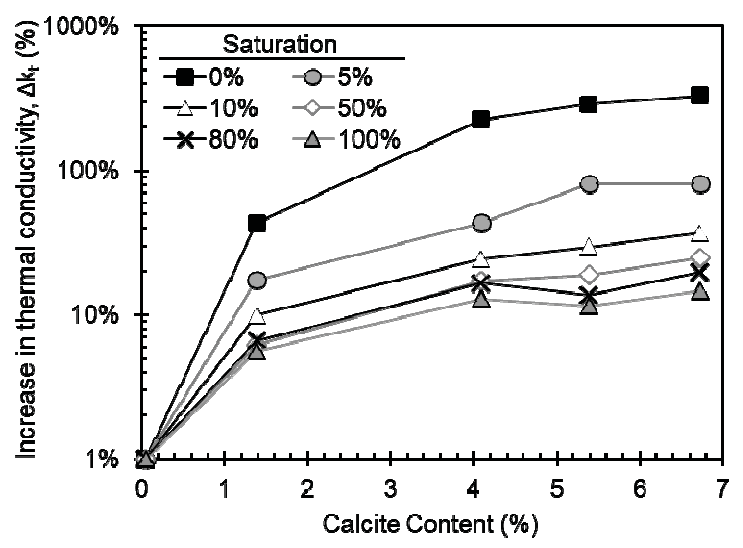

Fig. 7. Increase in thermal conductivity as a function of calcite content and degree of saturation.

\subsection{Evolution of thermal conductivity during hanging column desaturation}

The treated and untreated columns were subjected to suction values of up to $5 \mathrm{kPa}$ to obtain their air entry values and one scanning curve. Fig. 8 presents the air entry values obtained for the five columns. The results show an increase in AEV when CC increased from $0 \%$ to $4.1 \%$. However, further increases in $\mathrm{CC}$ did not result in measurable increases in the AEV. The results suggest a decrease in average pore size as the calcite content is increased to $4.1 \%$.

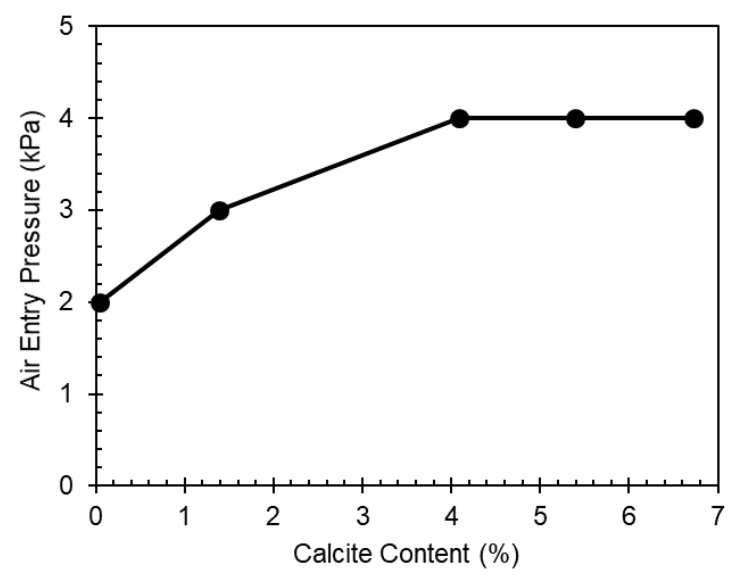

Fig. 8. Effect of calcite content on air entry pressure. 
The scanning curves for the treated and untreated columns followed similar trends, where the degree of saturation and the thermal conductivity decreased as the suction was increased past the AEV. Fig. 9 shows the scanning curve obtained from Column $3(\mathrm{CC}=5.4 \%)$. The evolution of the degree of saturation and thermal conductivity follow similar trends with suction, in agreement with $[6,16,21]$. In addition, the scanning curves show that after the suction is returned to $0 \mathrm{kPa}$, the degree of saturation and the $\mathrm{k}_{\mathrm{t}}$ are smaller than the initial value, highlighting the hysteresis in both relationships, likely due to the "ink-bottle effect and changes in fabric during caused by variations in suction [e.g. 16].
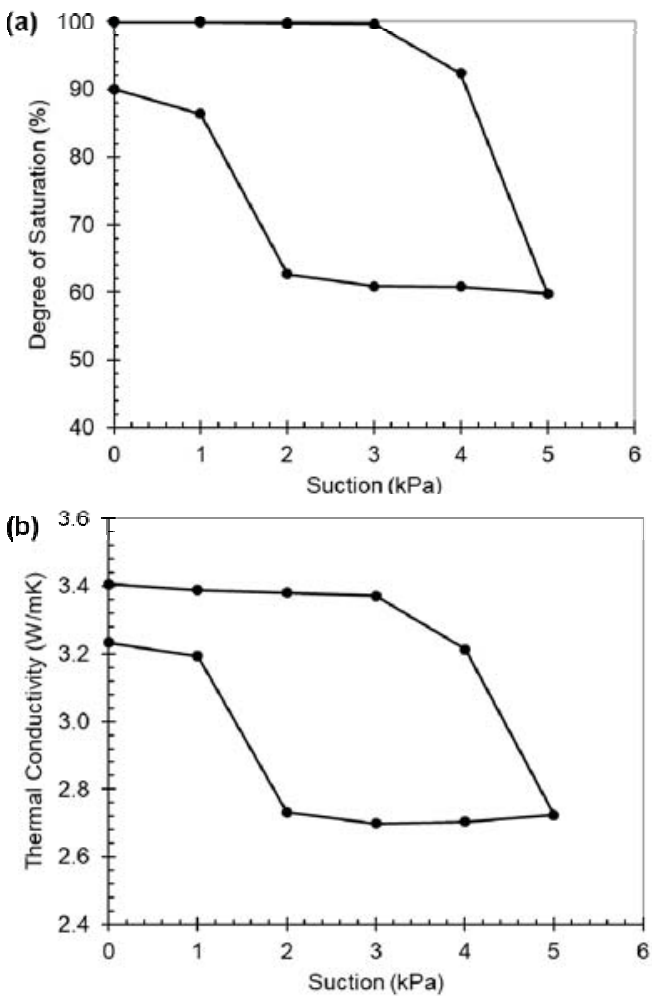

Fig. 9. Scanning curves for saturation and thermal conductivity.

\section{Discussion}

The efficiency of energy piles and ground source heat pump systems can be compromised in arid areas or areas with a deep water table because of the low thermal conductivity of soils with low degrees of saturation. The results presented herein suggest that MICP treatment is a viable method to increase the efficiency of those systems, as the $\mathrm{k}_{\mathrm{t}}$ of sandy soil was shown to increase by $330 \%, 81 \%$, and $37 \%$ for soils with degrees of saturation of $0 \%, 5 \%$, and $10 \%$, respectively, as the calcite content was increased to $6.7 \%$ (Fig. 7). Similarly, MICP treatment could help increase the rate of heat dissipation in applications such as buried electric cables. However, the results presented herein also indicate that only minor improvements in $\mathrm{k}_{\mathrm{t}}$ can be expected in saturated soils.
The results of this investigation also indicate that, under saturated conditions, the relationship between shear wave velocity and the thermal conductivity is linear (Fig. 3). A plausible explanation is that both measurements depend on the interparticle contact area, which is increased as CC increases. These results also suggest that $\mathrm{k}_{\mathrm{t}}$ may be used to monitor the cementation levels and contact quality during MICP in a similar way as $\mathrm{V}_{\mathrm{S}}$.

The relationship between $\mathrm{k}_{\mathrm{t}}$ and $\mathrm{CC}$ was found to be linear for any degree of saturation (Fig. 5). An analytical relationship can be developed for the thickness of a layer of cement around mono-sized spherical particles assuming a mode of precipitation where the cement evenly covers the surface of the particles [22]. This relationship can be used to determine the growth of the contact diameter and contact area with increasing level of cementation. These equations are:

$$
\begin{aligned}
& t=r\left((C C+1)^{1 / 3}-1\right) \\
& d_{\text {contact }}=\left(8 t r-4 t^{2}\right)^{1 / 2} \\
& A_{\text {contact }}=\pi\left(d_{\text {contact }} / 2\right)^{2}
\end{aligned}
$$

where $r$ is the radius of the particle, $t$ is the thickness of the cement layer, $\mathrm{CC}$ is the calcite content by mass, and $\mathrm{d}_{\text {contact }}$ and $\mathrm{A}_{\text {contact }}$ are the diameter and area of the interparticle contacts. Values calculated for $\mathrm{d}_{\text {contact }}$ and $\mathrm{A}_{\text {contact }}$ for a system composed of mono-sized spheres with a diameter of $0.26 \mathrm{~mm}$ are shown in Fig. 10. The rate of increase in contact diameter with increasing CC decays following a power-law, while the contact area increases at a more uniform rate with a near linear relationship for CC values between 0 to $20 \%$. This linear relationship between $\mathrm{A}_{\text {contact }}$ and $\mathrm{CC}$ can thus explain the linear relationship between $\mathrm{k}_{\mathrm{t}}$ and $\mathrm{CC}$, assuming that $\mathrm{CC}$ does not affect the rate at which heat is transferred through the water phase for soils at the same degree of saturation but with different CC magnitudes.

This experimental program only investigated the relationship between $\mathrm{k}_{\mathrm{t}}$, saturation, and $\mathrm{CC}$ for a quartz poorly graded sand. Future work should focus on evaluating this relationship for sands with different mineralogy as well as for well-graded sands. In addition, future research should further investigate the changes in air entry value and soil water retention curve characteristics as a result of biocementation.

\section{Conclusions}

This paper presents the results of an investigation on the effects of MICP treatment and degree of saturation on the thermal conductivity of poorly-graded quartz sand. Four soil columns were subjected to MICP treatment, resulting in a uniform distribution of cementation within columns with calcite contents ranging between $1.4 \%$ and $6.4 \%$. Measurements of thermal conductivity, shear wave velocity, and $\mathrm{pH}$ were obtained during MICP treatment. The $\mathrm{k}_{\mathrm{t}}$ and $\mathrm{V}_{\mathrm{S}}$ measurements during treatment have a linear relationship, suggesting that the former can 
also be used to monitor cementation levels and contact quality.
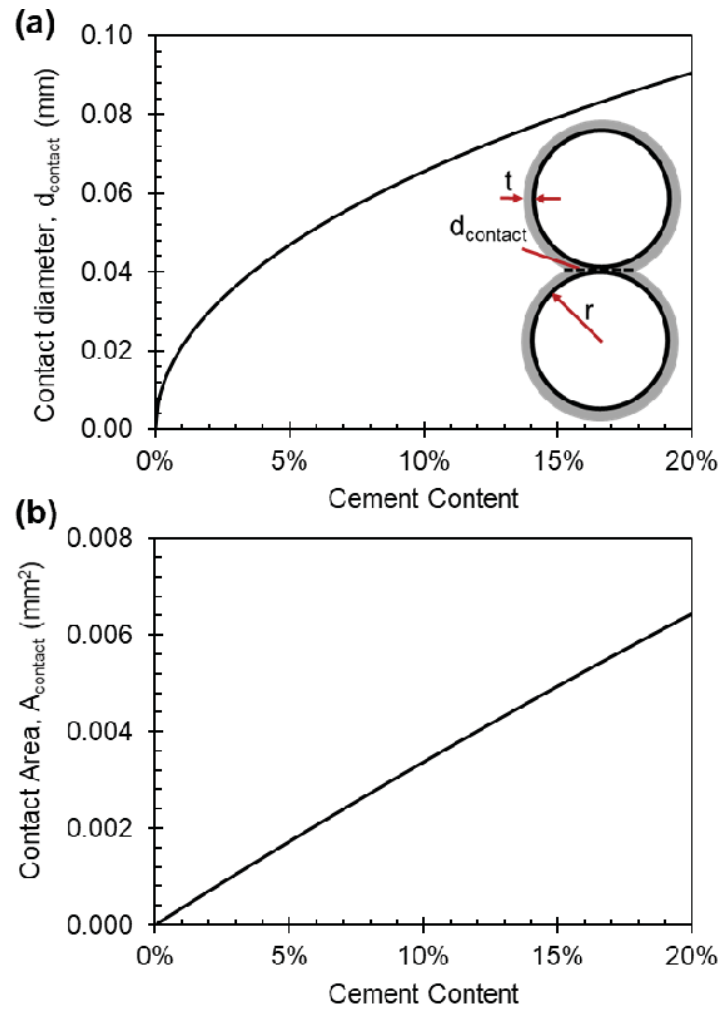

Fig. 10. (a) Diameter of contact and (b) contact area as a function of calcite content for an assembly of mono-sized spheres $(\mathrm{t}=$ cement layer thickness, sphere radius, $\mathrm{r}$, of 0.13 $\mathrm{mm}$, initial contact diameter, $\mathrm{d}_{\text {contact, }}$ of $0 \mathrm{~mm}$ ).

After treatment, columns were slowly desaturated, and results indicated that MICP treatment resulted in significantly larger increases in $\mathrm{k}_{\mathrm{t}}$ for dry conditions than for saturated conditions. In fact, an increase in $\mathrm{k}_{\mathrm{t}}$ of $330 \%$ was observed for dry conditions, while the increase was near $15 \%$ for saturated conditions. Scanning curves at suction values between 0 and $5 \mathrm{kPa}$ were obtained for each column, indicating that the air entry value increased as the $\mathrm{CC}$ was increased up to $4.1 \%$. However, no further increase in air entry values were observed in columns with larger $\mathrm{CC}$ values. In addition, the scanning curves which compared degree of saturation versus suction and thermal conductivity versus suction were remarkably similar to each other over the range of suction pressures examined. The results presented herein suggest that MICP treatment may be a viable option to increase the thermal conductivity of soils with low saturation values, which may benefit applications such as energy piles, ground source heat pump systems, and buried electrical cables. However, further work is needed to evaluate the effect of biocementation on the thermal conductivity and soil water retention curves of sands with different mineralogy and wider gradations.
The authors would like to thank Charles Graddy and Alexandra San Pablo of the Center for Biomediated and Bioinspired Geotechnics (CBBG) at UC Davis for their assistance with preparing inoculation solutions and guidance during MICP treatments and monitoring. Financial support provided by the UC Davis College of Engineering is acknowledged. This material is based upon work supported in part by the National Science Foundation (NSF) under NSF CA No. EEC-1449501. Any opinions, findings and conclusions or recommendations expressed in this material are those of the author(s) and do not necessarily reflect those of the NSF.

\section{References}

1. H Brandl. Geotechnique 56, 2 (2006).

2. G. Kong, D. Wu, H. Liu, L. Laloui, X. Cheng, X. Zhu. Int. J. En. Res., 43, 1 (2014).

3. O.T. Farouki. CRREL Monograph (US Army Corps of Engineers, Hanover, N.H., 1981).

4. T.S. Yun, J.C. Santamarina, Gran. Matt. 10, March (2008).

5. J. Côté, J.M. Konrad. Int. J. Heat Mass Trans. 42, 2 (2009).

6. W.J. Likos, J. Geotech. Geoenv. Eng. 140, 5 (2014).

7. C. Lee, T.S. Yun, S. Choi. Materials. 8, 7 (2015).

8. B.M. Wallen, K.M. Smits, T. Sakikim S.T. Howington, C. Deepagoda. Soil Sci. Soc. Am. J. 80, 3 (2016).

9. C. Lee, H.S. Suh, B. Yoon, T.S. Yun. Acta Geotech. 12, 3 (2017).

10. O. Johansen. CRREL Monograph (US Army Corps of Engineers, Hanover, N.H., 1975).

11. X. Hu, J. Du, S. Lei, B. Wang. Int. J. Heat Mass Trans. 44, 1, (2001).

12. J. Côté, J.M. Konrad. Can. Geotech. J. 42, 2 (2005).

13. S. Lu, T. Ren, Y. Gong, R. Horton. Soil Sci. Soc. Am. J. 71, 1 (2007).

14. S.X. Chen. Heat Mass Trans. 44, August (2008).

15. Y. Dong, J.S. McCartney, N. Lu. Geotech. Geol. Eng. 33, 2 (2015).

16. W.J. Likos. Geotech. Geol. Eng. 33, 2 (2015).

17. S. Venuleo, L. Laloui, D. Terzis, T. Hueckel, M. Hassan. Geotech. Lett. 6, 1 (2016).

18. A. Martinez, L. Huang, M.G. Gomez. Geotech. Lett. 9, 1 (2019).

19. JS. McCartney, LF.S. Villar, J. Zornberg. $1^{\text {st }}$ Pan American Geosynthetics Conference and Exhibition. (2008).

20. A.L. Fernandez, J.C. Santamarina. Can. Geotech. J. 38, 1 (2001).

21. K.M. Smits, T. Sakiki, A. Limsuwat, T.H Illangesakare. Vad. Zone J. 9, 1 (2010).

22. J.C. Santamarina, K.A. Klein, M.A. Fam. Soils and Waves: Particulate Materials Behavior, Characterization and Process Monitoring. Wiely. 